\title{
Hydrazinecarbothioamide Derivative as an Effective Inhibitor for Corrosion Control: Electrochemical, Surface and Theoretical Studies
}

\author{
Manjunath Bairy ${ }^{1} \cdot$ Mikitha Pais $^{1} \cdot$ P. Preethi Kumari ${ }^{1} \cdot$ Suma A. Rao ${ }^{1}$ (i)
}

Received: 17 February 2021 / Revised: 11 October 2021 / Accepted: 26 October 2021 / Published online: 9 November 2021

(C) The Author(s) 2021

\begin{abstract}
Aluminium has played a significant role in the advancement of metal matrix composites (MMC) and has drawn the attention of researchers since $\mathrm{Al}$ composites find extensive application in aerospace, military and automobile industries. This paper describes the corrosion property of $6061 \mathrm{Al}-15 \mathrm{vol} \%$. $\mathrm{SiC}_{(\mathrm{p})}$ composites in hydrochloric acid medium. This composite with high strength-to-weight ratio and other alluring properties undergoes corrosion in acid media and a study has been made in 0.5 M hydrochloric acid using (2Z)-2-(2-hydroxy-3methoxybenzylidene) hydrazinecarbothioamide (HCT) as an inhibitor. Results of the electrochemical studies and surface morphology are presented. With the increase in HCT concentration, inhibition efficiency increased. But efficiency decreased with an increase in temperature. The maximum efficiency was found to be $56.8 \%$ for the addition of $10 \times 10^{-5} \mathrm{M} \mathrm{HCT}$ concentration at $303 \mathrm{~K}$. The inhibitor was found to behave as a mixed inhibitor affecting both anodic metal dissolution reaction and cathodic hydrogen evolution to the same extent. The HCT molecules were found to physisorb over the Al-composite surface and adsorption followed Langmuir's adsorption isotherm. Adsorption of HCT was confirmed by scanning electron microscopy (SEM) and atomic force microscopy (AFM). Computational studies using density functional theory (DFT) supported experimental findings. Density functional theory calculations gave a clear insight into the mechanistic aspects of corrosion inhibition.
\end{abstract}

Suma A. Rao

suma.rao@manipal.edu

Department of Chemistry, Manipal Institute of Technology, Manipal Academy of Higher Education, Manipal 576104, India 


\section{Graphic Abstract}

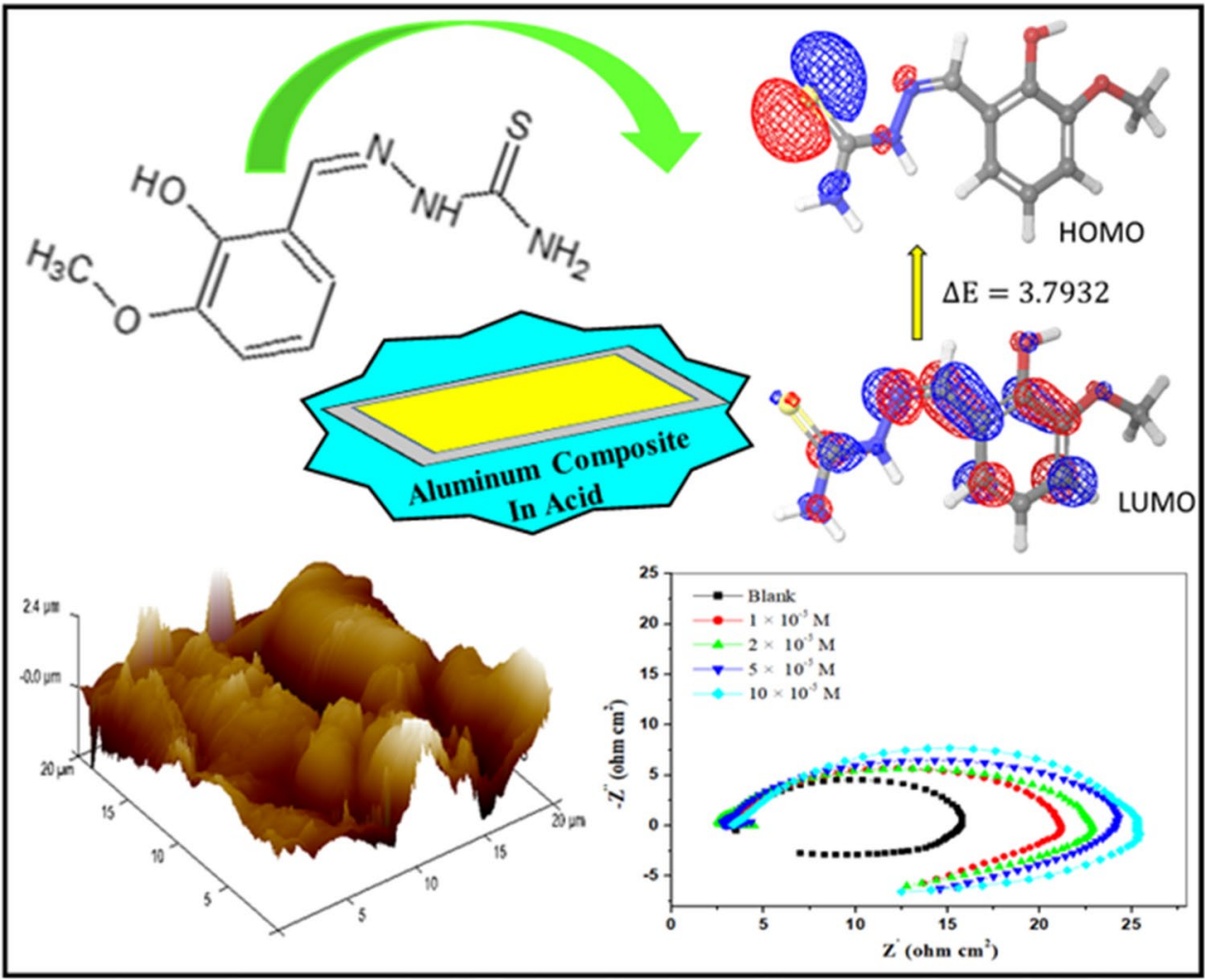

Keywords $6061 \mathrm{Al}-15 \mathrm{vol} \% \mathrm{SiC}(\mathrm{p})$ composite $\cdot$ Acid corrosion $\cdot$ Hydrazide $\cdot$ Electrochemical studies $\cdot$ Surface morphology $\cdot$ Density functional theory

\section{Introduction}

Aluminium, an industrially important metal, tends to undergo severe corrosion in various corrosive agents. This has been a problem to the industrial sectors for years and posing many problems even today [1]. However presence of thin continuous layer of aluminium oxide film makes aluminium good corrosion resistant material [2]. Aluminium metal and its alloys are not utilized much in the fields where high strength and stiffness for its applications are required. Ordinarily, to upgrade the strength, these are strengthened with $\mathrm{SiC}$ particulates to make it a metal matrix composite where $\mathrm{Al}$ is the matrix and $\mathrm{SiC}$ is the reinforcement. The silicon carbide reduces the density of $\mathrm{Al}$ and improves its stiffness and wear resistance. Aluminium matrix composite possess high Young's modulus/density and yield strength/density ratios together with tailorable coefficient of thermal expansion and high thermal conductivity. The composite so formed has a lower density, higher strength-to-weight ratio, and high stiffness and hence finds applications in automobile, marine, aerospace, rail transport, building and construction industries, offshore applications and other related sectors. The addition of non-metallic particulates makes the surface inhomogeneous and causes discontinuities in the oxide layer, making it more vulnerable to corrosion $[3,4]$. In the presence of corrosives, a galvanic type of corrosion occurs, and due to the inhomogeneity, the corrosion rate will be faster. The preferential localized attack has been based on factors, such as reactive silicon carbide, matrix, presence of crevices and pores, processing routes, presence of secondary phases and the volume percentage of reinforcement $[5,6]$. During the industrial applications, these materials, generally speaking, come into contact with acids or bases during the cycles like cleaning, pickling, etc. The acids or bases used here will consume the material and cause corrosion. In Industry, the most preferred technique for mitigation of corrosion of these composites in solution phase is the application of inhibitors. Organic heterocyclic compounds containing hetero atoms $\mathrm{N}, \mathrm{O}$, and $\mathrm{S}$ are reported to be excellent inhibitors for the corrosion of Al-composites [7-9]. The literature review shows that hydrazide derivatives act as effective inhibitors for the corrosion of steel in the acid medium [10-17]. In spite of 
the good corrosion inhibition characteristics of hydrazide derivatives, not much is reported for using them as inhibitors for aluminium and aluminium composites[18-20]. In this work, we have explored the application of (2Z)-2-(2hydroxy-3-methoxybenzylidene) hydrazinecarbothioamide (HCT)-a hydrazide derivative-as a corrosion inhibitor for the corrosion of $6061 \mathrm{Al}-15 \mathrm{vol} \% \mathrm{SiC}_{(\mathrm{p})}$ composite in $0.5 \mathrm{M} \mathrm{HCl}$ medium adopting electrochemical test methods. Work involves the study of the effect of concentration of HCT and the effect of temperature on the inhibition efficiency of HCT and to arrive at the mechanism of corrosion inhibition of $6061 \mathrm{Al}-15 \mathrm{vol} \% \mathrm{SiC}_{(\mathrm{p})}$ in $0.5 \mathrm{M} \mathrm{HCl}$ solution from thermodynamic and kinetic parameters of this corroding system. The techniques used for the study involved potentiodynamic polarisation, electrochemical impedance spectroscopy, scanning electron microscopy and atomic force microscopy.

\section{Experimental}

\subsection{Material}

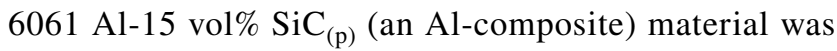
utilized in the current investigation. Composition of base alloy is given in Table 1.

The cylindrical-shaped coupon of $1 \mathrm{~cm}^{2}$ cross sectional surface area were chosen and its end surface was prepared by grinding and polishing with successive grit grade emery and disc polishing with levigated $\mathrm{Al}_{2} \mathrm{O}_{3}$ suspension. It was then mounted along with a concealed copper wire for electrical contact with coupon utilizing cold setting resin, exposing only the polished surface. The uncovered region of the mounted specimen was cleaned and disc polished again to get mirror finish.

Table 1 Composition of the base material (Al 6061)

\begin{tabular}{llllll}
\hline Elements & $\mathrm{Cr}$ & $\mathrm{Cu}$ & $\mathrm{Mg}$ & $\mathrm{Si}$ & $\mathrm{Al}$ \\
\hline Composition (wt\%) & 0.01 & 0.02 & 0.61 & 1.00 & 98.36 \\
\hline
\end{tabular}

\subsection{Preparation of the Medium}

A standard stock solution of $\mathrm{HCl}(1 \mathrm{M})$ was prepared from $36 \% \mathrm{AR}$ grade $\mathrm{HCl}$ and standardized by volumetric titration against a pre-standardised alkali solution. The solution of $0.5 \mathrm{M}$ was prepared as and when required by diluting the appropriate volume of the stock solution with double distilled water.

\subsection{Preparation of HCT}

In a $250 \mathrm{~mL}$ round bottom flask, equimolar concentration of 2-hydroxy-3-methoxybenzaldehyde ( $3 \mathrm{mmol}$ ) and thiosemicarbazide $(3 \mathrm{mmol})$ were mixed and dissolved in a minimum amount of ethanol. Then, two to three drops of glacial acetic acid were added to it, and it was refluxed for three hours. (2Z)-2-(2-hydroxy-3-methoxybenzylidene) hydrazinecarbothioamide (HCT), a white solid was formed, which was then filtered, washed, and dried [21]. The reaction is given in Scheme 1.

\subsection{Electrochemical Measurements}

The work station used in electrochemical investigations was $\mathrm{CH}$ instruments USA model 604E arrangement with beta version software. Multi neck Pyrex glass flat bottomed flask with provision for three electrodes was used as a cell for electrochemical measurements. The cell consisted of calomel as the reference, platinum as the counter, and Alcomposite as the working electrode. These electrodes were dipped in $0.5 \mathrm{M} \mathrm{HCl}$ solution, and open circuit potential (OCP) was recorded at the end of $600 \mathrm{~s}$. The experimental cell was placed inside a calibrated thermostat, and all values were recorded under unstirred conditions of the medium.

In the Electrochemical Impedance Spectroscopy(EIS) study, an AC signal of a small amplitude of $10 \mathrm{mV}$ was applied to the system in the frequency range of $100 \mathrm{kHz}$ to $0.01 \mathrm{~Hz}$ at OCP, and the response of the system was recorded [22]. The obtained Nyquist plot is fitted into a suitable equivalent circuit using Zimpwin software 3.1.

Potentiodynamic polarization study was conducted immediately after impedance measurement without further
Scheme 1 Synthetic route of HCT

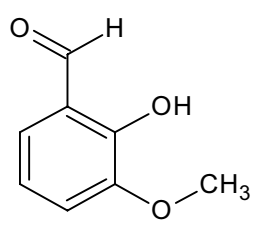

2-hydroxy-3methoxybenzaldehyde

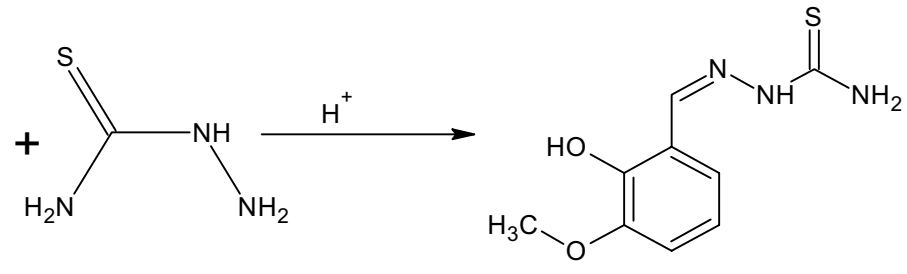

Thiosemicarbazide methoxybenzylidene)hydrazinecarbothioamide 
surface treatment. Potentiodynamic polarization were carried out in the absence and the presence of inhibitor by polarising the specimen each time from $-250 \mathrm{mV}$ cathodic to $+250 \mathrm{mV}$ anodic with respect to the $\mathrm{OCP}$, at a scan rate of $1 \mathrm{mVs}^{-1}$. Potentiodynamic polarization curves of Potential vs. $\log$ (current) were generated to get various electrochemical parameters.

\subsection{Quantum Chemical Calculations}

Schrodinger software (Maestro Material Science) was used to carry out the quantum chemical calculations. The geometrical optimization for investigated inhibitor HCT was done using the density functional theory (DFT). Using the Hybrid functional with the correlation functional (B3LYP) and $6-31 \mathrm{G}^{* *}$ as the basis set, calculations were done. Frontier molecular orbital (FMO) energies were calculated and discussed in detail for neutral and protonated HCT. Different theoretical parameters like the energy gap $(\Delta E)$, hardness $(\eta)$, and softness $(\sigma)$ electronegativity $(\chi)$, global electrophilicity $(\omega)$, nucleophilicity $(\varepsilon)$ fraction of electron transferred $(\Delta N)$ were evaluated using relevant equations. Mulliken charge population was evaluated. The dipole moment of neutral and protonated inhibitor molecule was computed, and comparison was discussed [23-25].

\subsection{Surface Morphological Studies}

The Scanning electron microscopy (SEM) images of the corroded specimens in the absence and the presence of inhibitor were analysed using model (JEOL JSM-6380L). The surface roughness values were determined using the Atomic force microscopy (AFM) technique with the 1B342 Innova model.

\section{Results and Discussion}

\subsection{FTIR Characterization Result of HCT}

The yield of the product obtained as described under section "Preparation of HCT" was $0.6 \mathrm{~g}(89 \%)$. Molecular formula was found to be $\mathrm{C}_{9} \mathrm{H}_{11} \mathrm{~N}_{3} \mathrm{O}_{2} \mathrm{~S}$. The melting point was in the range of $206-208{ }^{\circ} \mathrm{C}$.

Figure 1 shows the FTIR spectrum of HCT. The peaks at $3456 \mathrm{~cm}^{-1}$ and $3338 \mathrm{~cm}^{-1}$ may be due to symmetric and asymmetric stretching frequency of $-\mathrm{N}-\mathrm{H}$ bond in the primary amino group. The peak at $3155 \mathrm{~cm}^{-1}$ may be due to the $-\mathrm{OH}$ stretching frequency. The peak at $3028 \mathrm{~cm}^{-1}$ can be assigned for Ar-H stretching frequency. The peak at $1585 \mathrm{~cm}^{-1}$ is due to $\mathrm{C}=\mathrm{N}$ stretching. In the compounds where the carbon in the $\mathrm{C}=\mathrm{S}$ group is connected to one or two nitrogen atoms, the $\mathrm{C}=\mathrm{S}$ vibration is not localized; however, three bands seem to appear in the region $1395-1570 \mathrm{~cm}^{-1}, 1260-1420 \mathrm{~cm}^{-1}$, and $940-1140 \mathrm{~cm}^{-1}$, this is due to strong vibrational coupling effects [26].

\subsection{Potentiodynamic Polarization (PDP) Studies}

The potentiodynamic polarization curves for the dissolution of $\mathrm{Al}$-composite in $0.5 \mathrm{M} \mathrm{HCl}$ with and without HCT are

Fig. 1 FTIR spectrum of HCT

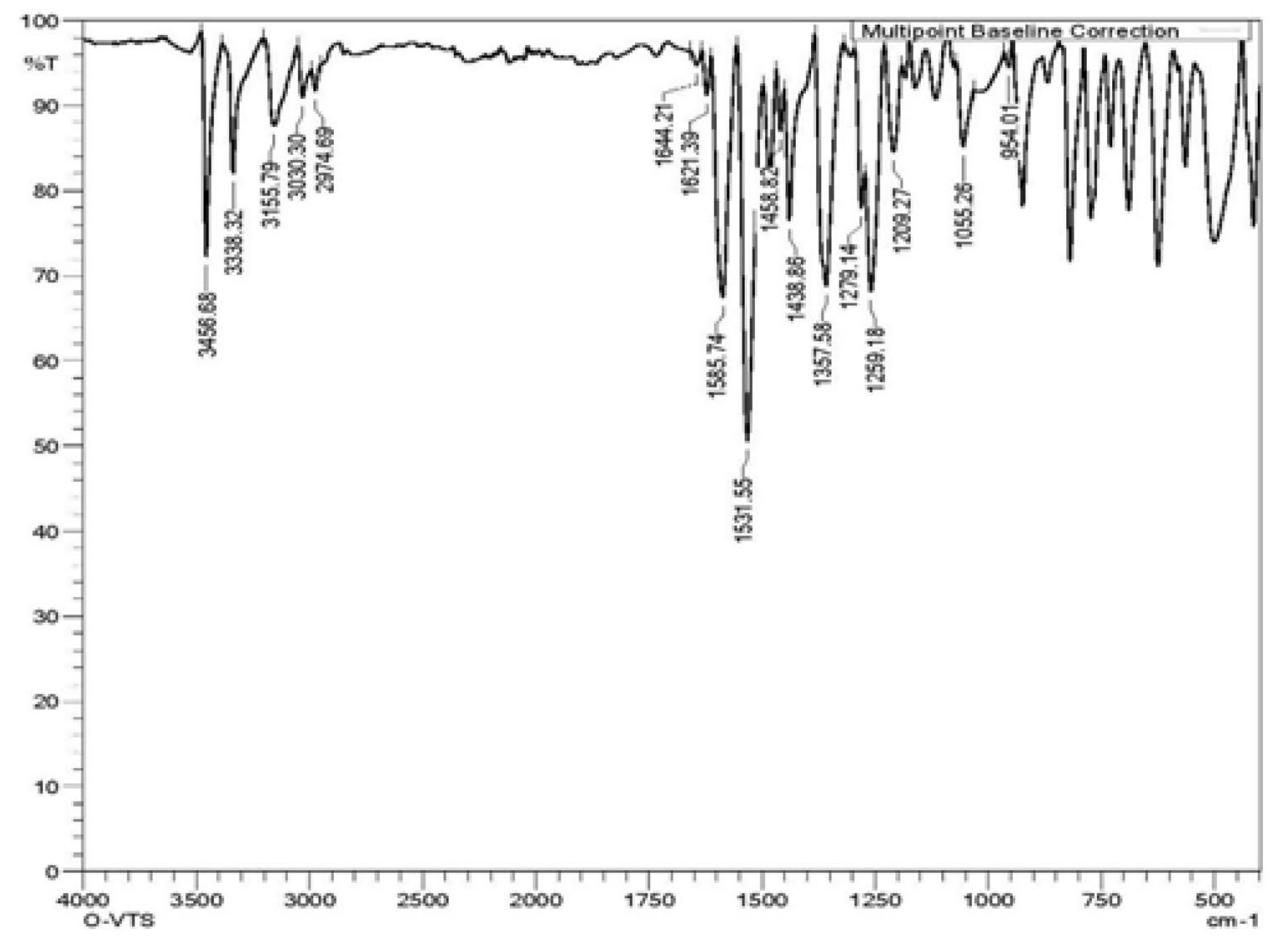


shown in Fig. 2. Various electrochemical parameters like corrosion current density $\left(i_{\text {corr }}\right)$, corrosion potential $\left(E_{\text {corr }}\right)$, Cathodic slope $\left(-\beta_{c}\right)$ and anodic slope $\left(\beta_{a}\right)$ were obtained from potentiodynamic polarisation graphs. Corrosion rate and percentage inhibition efficiency (IE\%) are calculated using Eqs. (1) and (2), respectively.

$\mathrm{CR}\left(\mathrm{mm} \mathrm{year}^{-1}\right)=\frac{3270 \times M \times i_{\text {corr }}}{d \times n}$

$\mathrm{IE} \%=\frac{i_{\text {corr }}-i_{\text {corr(inh) }}}{i_{\text {corr }}} \times 100$

$i_{\text {corr }}$ and $i_{\text {corr(inh) }}$ are corrosion current density $\left(\mu \mathrm{A} \mathrm{cm}^{-2}\right)$ in the absence and presence of the inhibitor, 3270 is a constant, $M$ is the atomic mass of corroding material, $d=$ density of corroding material $\left(2.7 \mathrm{~g} \mathrm{~cm}^{-3}\right), n$ is the number of electrons involved in the reaction $(n=2)$ [27]

$\% \mathrm{I} . \mathrm{E}=\theta \times 100$

In Fig. 2, anodic curves represent metal dissolution and the cathodic curves stand for the hydrogen evolution process. The addition of reinforcements results in increase in the corrosion rate. The electrode potentials of silicon and aluminium are $-0.14 \mathrm{~V}$, and $-1.67 \mathrm{~V}$, respectively. Hence silicon carbide particulates will be cathodic and aluminium which act as anode undergoes dissolution due to galvanic corrosion. The surface is inhomogeneous, due to presence of particulates and results in increased corrosion rate.

In the absence of HCT, both the corrosion current density $\left(i_{\text {corr }}\right)$ and corrosion rate $(\mathrm{CR})$ showed an increasing trend with increase in temperature. This can be attributed to an increase in mobility of ions and also increase in conductance of the medium at higher temperature. However, in the

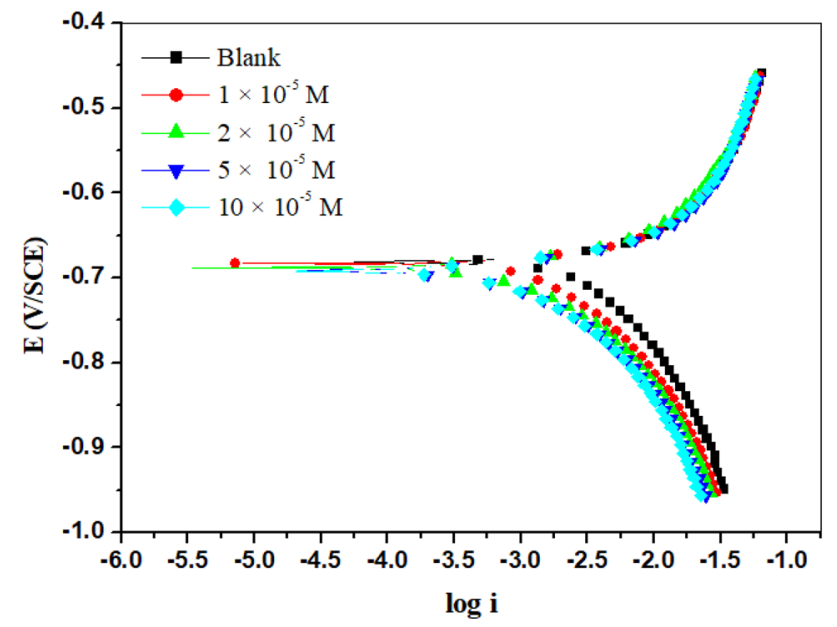

Fig. 2 PDP curves for aluminium composite in $0.5 \mathrm{M} \mathrm{HCl}$ at $303 \mathrm{~K}$ in the absence and presence of HCT presence of HCT the rate at which the increase in $i_{\text {corr }}$ and $\mathrm{CR}$ is not significant even with increase in temperature. That is, on the addition of HCT, the values of $i_{\text {corr }}$ and CR are decreased, resulting in higher \%IE values. This might be due to adsorption of HCT molecules on metal surface and hence the moiety part of the inhibitor molecule blocking the active sites which are responsible for the corrosion. Maximum efficiency of $56.8 \%$ was obtained at $303 \mathrm{~K}$ for $10 \times 10^{-5} \mathrm{M} \mathrm{HCT}$ concentration.

The values of both anodic and cathodic slopes as well as corrosion potential $\left(E_{\text {corr }}\right)$ did not vary much, which indicated that the addition of inhibitor did not alter significantly the mechanism of corrosion [27, 28]. But $i_{\text {corr }}$ shifted slightly to the left indicating lower current density at corrosion potential. Added inhibitor has brought down the corrosion rate by simple blocking effect. As per the reported literature [29], the inhibitor might be regarded as either anodic or cathodic if the value of corrosion potential exceeds by $\pm 85 \mathrm{mV}$ in the presence of the inhibitor when compared to the uninhibited solution. In the present study, the maximum difference observed was much less than that. Hence the inhibitor is considered as a mixed type of inhibitor. That is added inhibitor controls both anodic and cathodic reaction rates to the same extent and thus brings down the overall rate of corrosion. Results of potentiodynamic polarization experiments are tabulated in Table 2.

\subsection{Electrochemical Impedance Spectroscopy (EIS) Study}

Electrochemical impedance spectroscopy is one amongst the powerful tools used in electrochemistry to analyse and understand the mechanistic aspects of the electrode process. Figure 3 shows the Nyquist plots obtained for the acid corrosion of Al-composite with various concentrations of the HCT at $303 \mathrm{~K}$. Similar plots were recorded at $313 \mathrm{~K}$ and $323 \mathrm{~K}$. The Nyquist plot of aluminium composite consisted of two loops: high frequency (HF) capacitive loop and intermediate frequency (IF) inductive loop. The shape of the plots obtained agreed well with others reported in the literature [30-32].

The large capacitive loop represents the charge transfer resistance for the process of corrosion. This is a direct result of the oxidation of $\mathrm{Al}-\mathrm{CM}$ at the $\mathrm{M}+/ \mathrm{O}_{2}-/$ medium interface. $\mathrm{Al}^{3+}$ is formed as $\mathrm{Al}^{1+}$ loses its electrons. This is because of the movement of $\mathrm{Al}^{1+}$ from the $\mathrm{M}^{+} / \mathrm{O}^{2-}$ interface through the $\mathrm{O}^{2-}$ /medium interface, which forms hydroxyl and oxide ions at the oxide/corrosive interface [30].

The diameter of the semicircle of Nyquist plots increased with the addition of increased concentration of HCT. This suggests that the resistance of the composite material for anodic oxidation increased with a rise in HCT concentration. This resistance is mainly attributable to the barrier film 
Table 2 Results of PDP measurements obtained for $\mathrm{Al}-15 \mathrm{vol} \% \mathrm{SiC}_{(\mathrm{p})}$ in $0.5 \mathrm{M} \mathrm{HCl}$ in the absence and presence of HCT at different temperatures

\begin{tabular}{llllllll}
\hline $\begin{array}{l}\text { Temp } \\
(\mathrm{K})\end{array}$ & $\begin{array}{l}{[\mathrm{HCT}]} \\
\left(\times 10^{-5} \mathrm{M}\right)\end{array}$ & $\begin{array}{l}E_{\text {corr }} \\
(\mathrm{mV})\end{array}$ & $\begin{array}{l}-\beta_{\mathrm{c}} \\
\left(\mathrm{V} \mathrm{dec}^{-1}\right)\end{array}$ & $\begin{array}{l}\beta_{\mathrm{a}} \\
\left(\mathrm{V} \mathrm{dec}^{-1}\right)\end{array}$ & $\begin{array}{l}i_{\text {corr }} \\
\left(\mathrm{mA} \mathrm{cm}^{-2}\right)\end{array}$ & $\begin{array}{l}\text { CR } \\
(\mathrm{mpy})\end{array}$ & $\%$ IE \\
\hline 303 & 0 & -681 & 5.503 & 4.923 & 2.677 & 1147 & - \\
& 1 & -683 & 6.462 & 5.025 & 1.578 & 676 & 41.0 \\
& 2 & -686 & 6.625 & 5.046 & 1.385 & 593 & 48.2 \\
& 5 & -688 & 6.894 & 5.462 & 1.259 & 539 & 53.1 \\
& 10 & -691 & 6.999 & 5.349 & 1.157 & 496 & 56.8 \\
313 & 0 & -682 & 5.509 & 4.826 & 3.744 & 1605 & - \\
& 1 & -689 & 5.845 & 4.759 & 2.469 & 1058 & 35.0 \\
& 2 & -689 & 6.199 & 4.949 & 2.170 & 930 & 42.0 \\
& 5 & -684 & 6.044 & 5.331 & 1.972 & 845 & 47.3 \\
& 10 & -688 & 6.017 & 4.961 & 1.720 & 737 & 54.0 \\
323 & 0 & -686 & 5.885 & 4.896 & 5.457 & 2340 & - \\
& 1 & -689 & 5.912 & 4.971 & 3.771 & 1617 & 30.9 \\
& 2 & -684 & 5.954 & 4.952 & 3.527 & 1512 & 35.3 \\
& 5 & -684 & 5.985 & 4.965 & 3.105 & 1331 & 43.1 \\
& 10 & -686 & 5.951 & 4.862 & 2.804 & 1202 & 48.6 \\
\hline
\end{tabular}

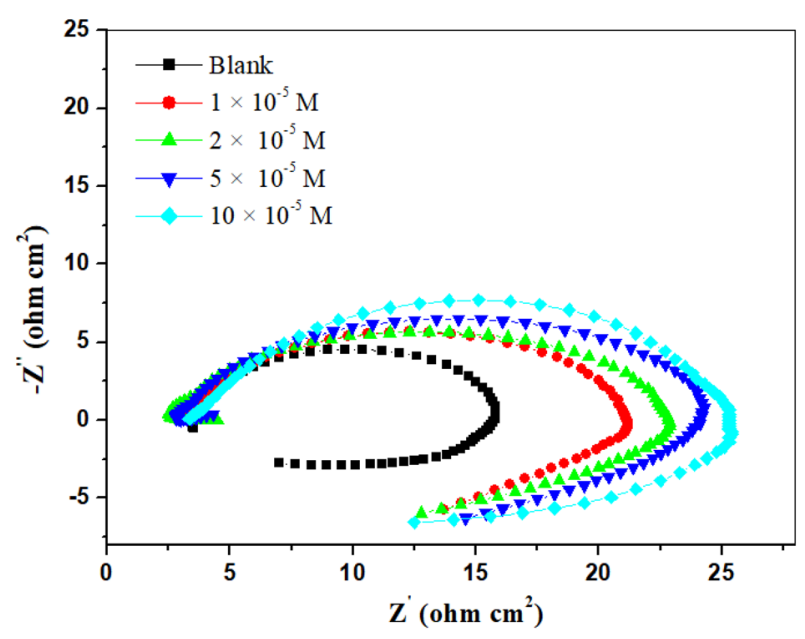

Fig. 3 Nyquist plots of aluminium composite in $0.5 \mathrm{M} \mathrm{HCl}$ at $303 \mathrm{~K}$ in the absence of HCT and for its different concentration

formation due to adsorption of the inhibitor on the surface of the composite material. The small inductive loop in the lower frequency region indicates the adsorption of HCT or the surface species.

The plots obtained are depressed semicircles, and the reason for this depression is the inhomogeneous nature of the surface, which may be due to the presence of particulates, corrosion products, and HCT molecules.

Nyquist plots were made to fit into an equivalent circuit using Zimpwin software 3.1. as shown in Fig. 4. An equivalent circuit of five elements which consisted of charge transfer resistance $\left(R_{\mathrm{CT}}\right)$, solution resistance $\left(R_{S}\right)$, inductive resistance $\left(R_{L}\right)$, inductive element $(L)$, and a constant phase element $(Q)$ was used. $R_{\mathrm{CT}}$ is parallel to $R_{L}$, and their equivalent is in series with $\mathrm{R}_{\mathrm{S}}$. Thus the polarization resistance $R_{P}$ can be found out as,

$R_{P}=\frac{R_{L} \times R_{\mathrm{CT}}}{R_{L}+R_{\mathrm{CT}}}$

The element $Q$ is used to replace the real double-layer capacitance $C_{d l}$. The impedance plots for composite materials are not perfect semicircles due to the frequency dispersion that occurs during impedance analysis as a result of surface inhomogeneity [33]. The actual value of the capacitance can be found out using the equation,

$C_{d l}=\frac{1}{\left(2 \times \pi \times R_{P} \times f_{\max }\right)}$

where $C_{d l}, R_{P}$ and $f_{\max }$ are the double-layer capacitance, the polarisation resistance, the frequency where the imaginary part of the impedance is maximum, respectively. The corrosion current density and polarization resistance are related inversely. Hence the percentage efficiency of inhibition can be calculated as,

$\mathrm{IE} \%=\frac{R_{P(\mathrm{inh})}-R_{P}}{R_{P(\mathrm{inh})}}$

where $R_{\mathrm{P}(\mathrm{inh})}$ and $R_{P}$ are the polarization resistance values for the inhibited and without the inhibitor solutions.

From Table 3, it is clear that the polarisation resistance value increased with the addition of HCT. Adsorption of HCT molecules has increased the resistance towards the corrosion by decreasing the flow of electrons. With increase in the concentration of HCT, the double-layer 
Fig. 4 a Equivalent circuit used to fit the experimental EIS data and the corresponding plot obtained for the corrosion of Al-composite at $303 \mathrm{~K}$, b equivalent circuit

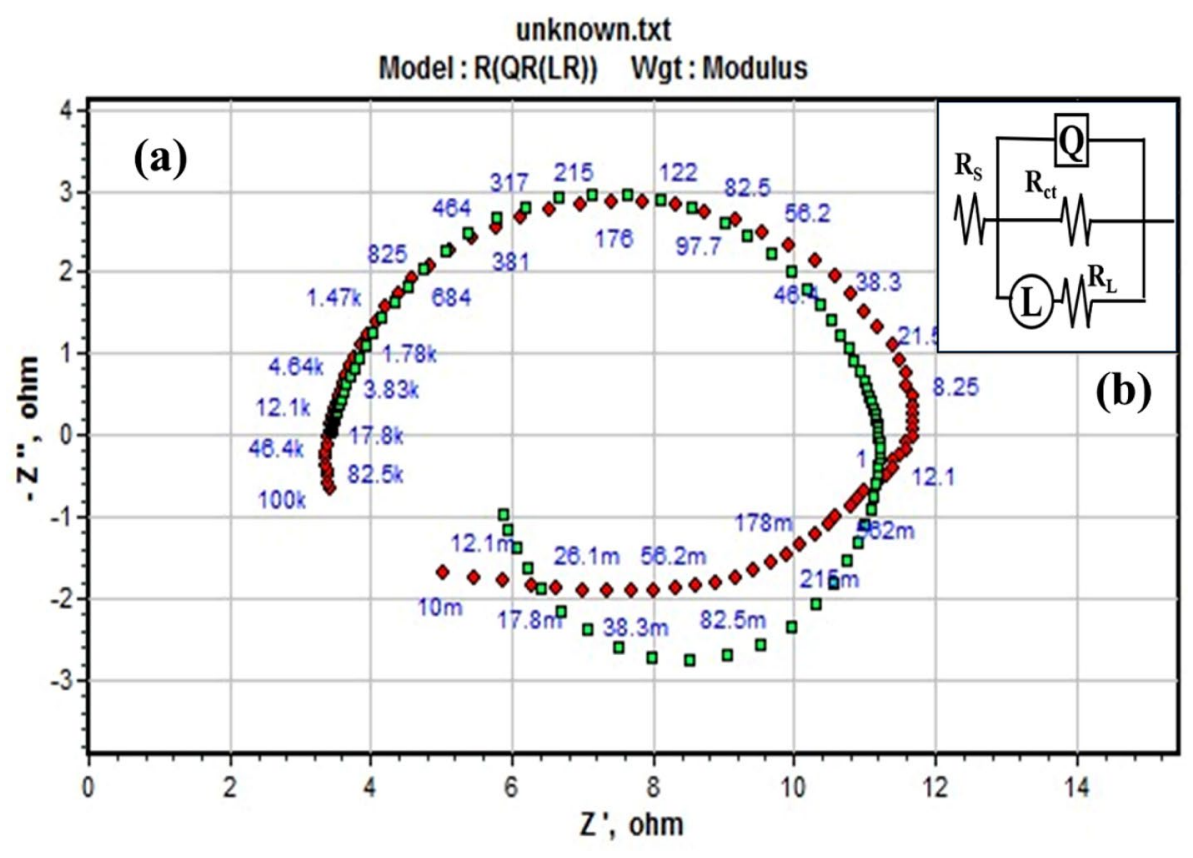

Table 3 Results of EIS experiments obtained for the aluminium composite in $0.5 \mathrm{M} \mathrm{HCl}$ at different temperatures and different concentrations of $\mathrm{HCT}$

\begin{tabular}{lccll}
\hline $\begin{array}{l}\text { Temp } \\
(\mathrm{K})\end{array}$ & $\begin{array}{l}\text { Conc. of } \\
\mathrm{HCT} \\
\left(\times 10^{-5} \mathrm{M}\right)\end{array}$ & $\begin{array}{l}\mathrm{R}_{\mathrm{p}} \\
(\mathrm{ohm} \mathrm{cm})\end{array}$ & $\begin{array}{l}\mathrm{C}_{\mathrm{dl}} \\
\left(\times 10^{-3} \mathrm{~F} \mathrm{~cm}^{-2}\right)\end{array}$ & $\%$ IE \\
\hline 303 & 0 & 7.058 & 5.038 & - \\
& 1 & 11.69 & 2.435 & 39.59 \\
& 2 & 13.02 & 1.912 & 45.79 \\
& 5 & 14.35 & 1.559 & 50.83 \\
313 & 10 & 15.54 & 1.321 & 54.59 \\
& 0 & 5.68 & 9.854 & - \\
& 1 & 8.43 & 5.034 & 32.59 \\
& 2 & 9.27 & 4.339 & 38.69 \\
& 5 & 10.54 & 3.275 & 46.10 \\
323 & 10 & 11.74 & 2.649 & 51.61 \\
& 0 & 4.473 & 0.719 & - \\
& 1 & 6.28 & 9.444 & 28.79 \\
& 2 & 6.69 & 8.023 & 33.20 \\
& 5 & 7.47 & 6.376 & 40.09 \\
& 10 & 8.19 & 4.866 & 45.39 \\
\hline
\end{tabular}

capacitance $C_{\mathrm{dl}}$ value has decreased. Typically, an electrical twofold layer is formed at the metal solution interface, which will be comparable to a capacitor. The inhibitor molecules adsorb over the metal surface and replace the surface water and some initially present molecules. This expands the thickness of the twofold layer. An increment in thickness will bring about a decline in the capacitance value [34].

\subsection{Evaluation of Kinetic Parameters}

Kinetic parameters can be evaluated by studying the corrosion and inhibition process at different temperatures. The activation energy $\left(E_{\mathrm{a}}\right)$ can be evaluated using Arrhenius Eq. (7) enthalpy of activation $\left(\Delta H_{a}^{\#}\right)$ and entropy of activation $\left(\Delta S_{a}^{\#}\right)$ from Transition state Eq. (8), respectively.

$\ln (\mathrm{CR})=B-\frac{E_{a}}{R T}$

$\ln (C R)=\ln \left(\frac{R T}{N h}\right)+\left(\frac{\Delta S^{\#}}{R}\right)-\left(\frac{\Delta H^{\#}}{R T}\right)$

where $B$ is the Arrhenius constant whose value is dependent on the metal type, $R$ is the universal gas constant $\left(8.314 \mathrm{~J} \mathrm{~K}^{-1} \mathrm{~mol}^{-1}\right), h$ is the Planck's constant $\left(6.626 \times 10^{-34} \mathrm{~J} \mathrm{~s}^{-1}\right)$, and $N$ is the Avogadro number $\left(6.023 \times 10^{23} \mathrm{~mol}^{-1}\right)$ [33]. Graphical representations of the data based on these equations are shown in Fig. 5a and b, respectively. Calculated kinetic parameters are listed in Table 4.

Energy of activation for composite to react in $0.5 \mathrm{M}$ $\mathrm{HCl}$ was $28.71 \mathrm{~kJ} \mathrm{~mol}^{-1}$. The value of the energy of activation increased with increase in the concentration of the added inhibitor. The maximum energy of activation of $44.96 \mathrm{~kJ} \mathrm{~mol}^{-1}$ was observed for the addition of $10 \times 10^{-5}$ HCT. A higher value of the energy of activation in the presence of an inhibitor is due to the adsorption of inhibitor molecules on the active sites of the metal surface forming a protective film and blocking and reducing the cathodic surface involving electron transfer to $\mathrm{H}^{+}$ions of the acid 

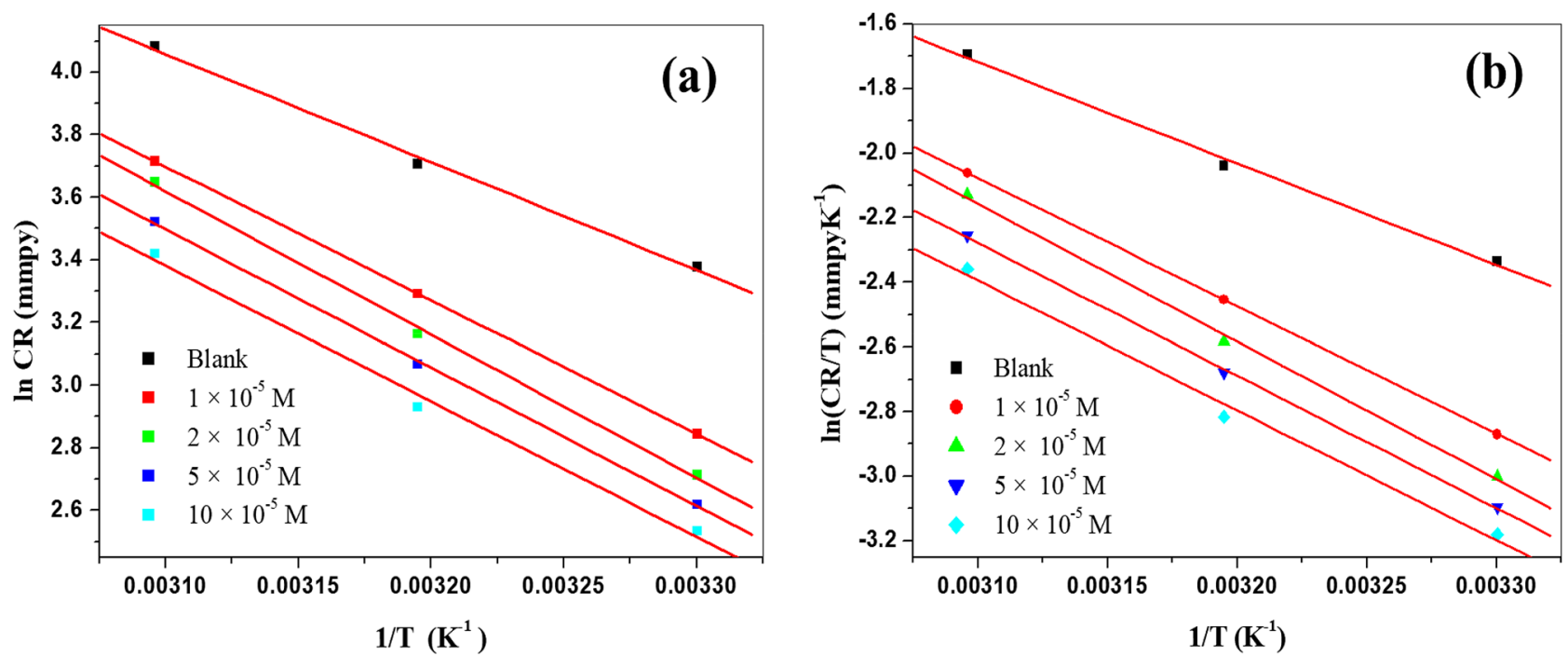

Fig. 5 Plot of $\mathbf{a} \ln (\mathrm{CR})$ vs $1 / T$ and $5, \mathbf{b} \ln (\mathrm{CR} / \mathrm{T})$ vs $1 / T$ for corrosion of Al-composite in $0.5 \mathrm{M} \mathrm{HCl}$ solution for different concentrations of HCT

Table 4 Activation parameters for the corrosion of Al-composite in $0.5 \mathrm{M} \mathrm{HCl}$ solution for different concentrations of HCT

\begin{tabular}{llll}
\hline $\begin{array}{l}\text { Conc. of HCT } \\
(\mathrm{M})\end{array}$ & $\begin{array}{l}E_{a} \\
\left.(\mathrm{~kJ} \mathrm{~mol})^{-1}\right)\end{array}$ & $\begin{array}{l}\Delta H^{\#} \\
\left(\mathrm{~kJ} \mathrm{~mol}^{-1}\right)\end{array}$ & $\begin{array}{l}\Delta S^{\#} \\
(\mathrm{~kJ} \mathrm{~mol}\end{array}$ \\
\hline 0 & 28.71 & 26.11 & -130.89 \\
$1 \times 10^{-5}$ & 35.44 & 32.84 & -113.01 \\
$2 \times 10^{-5}$ & 38.00 & 35.41 & -105.72 \\
$5 \times 10^{-5}$ & 41.71 & 38.45 & -98.46 \\
$10 \times 10^{-5}$ & 44.96 & 41.86 & -92.35 \\
\hline
\end{tabular}

medium. This results in an increase in hydrogen overvoltage and cathodic reaction becomes sluggish. Increase of inhibitor concentration makes the film to cover the metal surface to a greater extent and also making the film formed thicker (multimolecular layer) and consequently the rate of corrosion further decreases indicating that higher energy of activation is needed when concentration of inhibitor is higher. This observation supports the possible physisorption of inhibitor on the metal surface [35-37]. Enthalpy of activation is almost the same as that of the energy of activation. A negative value of entropy of activation suggests more orderliness during the formation of the activated complex [38].

\subsection{Adsorption Isotherm}

The fraction of the metal surface $(\theta)$ covered for various concentrations of the HCT was calculated as per Eq. 3. The obtained results were fit into different adsorption isotherms like Langmuir, Freundlich, Frumkin, and Temkin. In this study, Langmuir isotherm was the best fit for the experimental results, and it is given by the equation,

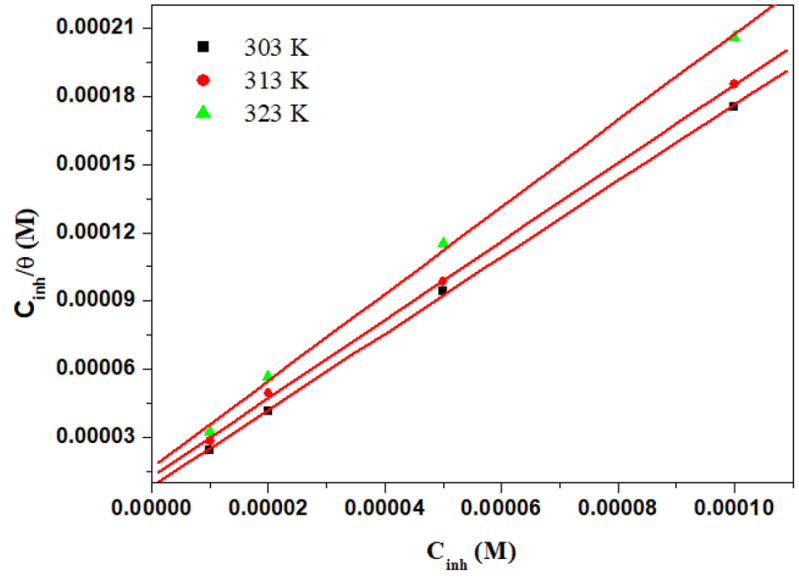

Fig. 6 Langmuir's Adsorption isotherm for the corrosion of Al-composite in $0.5 \mathrm{M} \mathrm{HCl}$ solution for various concentrations of HCT

$\frac{C_{\mathrm{inh}}}{\theta}=\frac{1}{K}+C_{\mathrm{inh}}$

where $K$ is the equilibrium constant for the adsorption or desorption process $\left(\mathrm{M}^{-1}\right), \theta$ is the surface covered, and $C$ is the concentration of HCT in the solution.

The plot, $C_{\text {inh }} / \theta$ versus $C_{\text {inh }}$ results in a straight line with $1 / K$ as the intercept. Figure 6 is the Langmuir adsorption isotherm for the adsorption of HCT on the aluminium composite surface. The linear correlation coefficient is almost close to unity. The values of slopes seem to deviate a little from unity; and this might be due to the lateral interaction of HCT molecules with the aluminium composite surface [39]. 
The relationship between the standard free energy change for the adsorption $\left(\Delta G_{\text {ads }}^{0}\right)$ and the adsorption/desorption constant $(\mathrm{K})$ is given by the equation,

$K=\frac{1}{55.5} \exp \left(-\frac{\Delta G_{\mathrm{ads}}^{0}}{R T}\right)$

In Eq. (10), $\mathrm{T}$ is the absolute temperature, $\mathrm{R}$ the universal gas constant and 55.5 is the concentration of water in solution in mol dm${ }^{-3}$. The standard enthalpy of adsorption $\left(\Delta H_{\text {ads }}^{0}\right)$ and standard entropy change $\left(\Delta S_{\text {ads }}^{0}\right)$ were then calculated using Gibbs-Helmholtz equation

$\Delta G_{\mathrm{ads}}^{0}=\Delta H_{\mathrm{ads}}^{0}-\mathrm{T} \Delta S_{\mathrm{ads}}^{0}$

The graph is plotted with $\Delta G_{\text {ads }}^{0}$ vs. temperature $(T)$ as shown in Fig. 7. Slope and intercept of the above equation were used to obtain the value of entropy of adsorption $\left(\Delta S_{\text {ads }}^{0}\right)$ and enthalpy of adsorption $\left(\Delta H_{\text {ads }}^{0}\right)$, respectively. Calculated thermodynamic parameters are tabulated in Table 5.

From Table 5, it can be observed that the free energy of adsorption $\left(\Delta G_{\text {ads }}^{0}\right)$ is $-39.64 \mathrm{~kJ} \mathrm{~mol}^{-1}$ suggesting the spontaneity of adsorption. As the value is close to $-40 \mathrm{~kJ} \mathrm{~mol}^{-1}$ implies there is the possibility of chemical adsorption. As per the reported literature, physical adsorption may have either a positive or negative value of enthalpy of adsorption

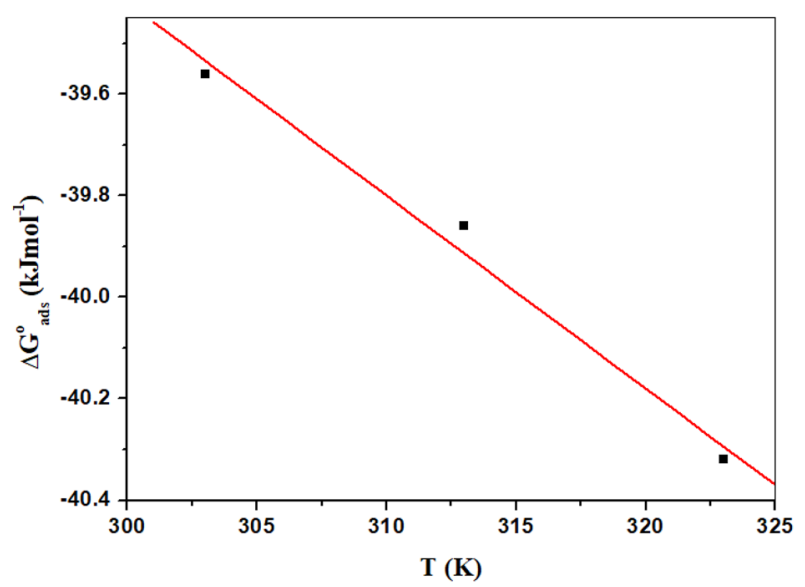

Fig. 7 Plot of $\Delta G_{\text {ads }}^{0}$ vs. $T$ for the corrosion of Al-composite in $0.5 \mathrm{M}$ $\mathrm{HCl}$ solution
$\left(\Delta H_{\text {ads }}^{0}\right)$ [40] but for chemical adsorption, it is a univocally positive value [41]. From Table 5, value $\Delta H_{\text {ads }}^{0}$ is around $-50 \mathrm{~kJ} \mathrm{~mol}^{-1}$. From these observations, it may be concluded that inhibitor molecule undergoes both physical and chemical adsorption with predominate physisorption. A decrease in the inhibition efficiency of HCT with an increase in temperature, further supports physical adsorption.

\subsection{Role of HCT in Corrosion Inhibition}

The $\mathrm{pH}$ at which the aluminium surface is neutral, i.e., the point of zero charge for aluminium, is 9.1. Since the medium is acidic, the surface will be positively charged. Therefore, chloride ions and the HCT molecules can adsorb through their negative centres. But in a highly acidic medium, there is a chance of protonation of HCT molecules. Water molecules may get attracted towards this negative layer through their hydrogen ends. But the protonated HCT molecules replace the water molecules and get adsorbed over the negative layer, preventing further oxidation of aluminium. Hence they isolate the metal surface from the action of the corrosive medium and thus control the further attack by the corrosive. The above mechanism and the mode of adsorption were further supported by quantum chemical calculations. Schematic representation of mechanism is shown in Fig. 8.

\subsection{Quantum Chemical Study}

Quantum chemical calculations were performed so as to understand the interaction between the inhibitor molecule and the surface of the composite material, using density functional theory. Insight in to the mode of adsorption of inhibitor molecule on the composite material is obtained from quantum chemical parameters like energy gap $(\Delta E) F$ raction of electrons transferred $(\Delta N)$ etc.

The energy gap is the difference between the highest occupied molecular orbital. ( $E_{\text {HOMO }}$ ) and lowest unoccupied molecular orbital $\left(E_{\mathrm{LUMO}}\right)$ of the inhibitor molecule as per the Pearson's Hard Soft Acid Base (HSAB) theory [42]. Further, $E_{\mathrm{HOMO}}$ is directly connected to ionization energy and hence susceptibility of a molecule towards electrophilic attack. $E_{\mathrm{LUMO}}$ is directly linked to electron affinity and thus vulnerability of a molecule towards nucleophilic attack [43].
Table 5 Thermodynamic parameters for the adsorption of HCT on Al-composite in $0.5 \mathrm{M} \mathrm{HCl}$ solution at different temperatures

\begin{tabular}{lllllll}
\hline $\begin{array}{l}\text { Temp } \\
(\mathrm{K})\end{array}$ & $\begin{array}{l}\mathrm{K} \\
\left(\times 10^{3} \mathrm{M}^{-1}\right)\end{array}$ & Slope & $R^{2}$ & $\begin{array}{l}\Delta G_{\text {ads }}^{0} \\
\left(\mathrm{~kJ} \mathrm{~mol}^{-1}\right)\end{array}$ & $\begin{array}{l}\Delta H_{\mathrm{ads}}^{0} \\
\left(\mathrm{~kJ} \mathrm{~mol}^{-1}\right)\end{array}$ & $\begin{array}{l}\Delta S_{\text {ads }}^{0} \\
\left(\mathrm{~J} \mathrm{~mol}^{-1}\right)\end{array}$ \\
\hline 303 & 123.0 & 1.67 & 0.999 & -39.64 & -48.48 & -29 \\
313 & 67.98 & 1.72 & 0.999 & -39.37 & & \\
323 & 59.65 & 1.90 & 0.999 & -39.05 & & \\
\hline
\end{tabular}




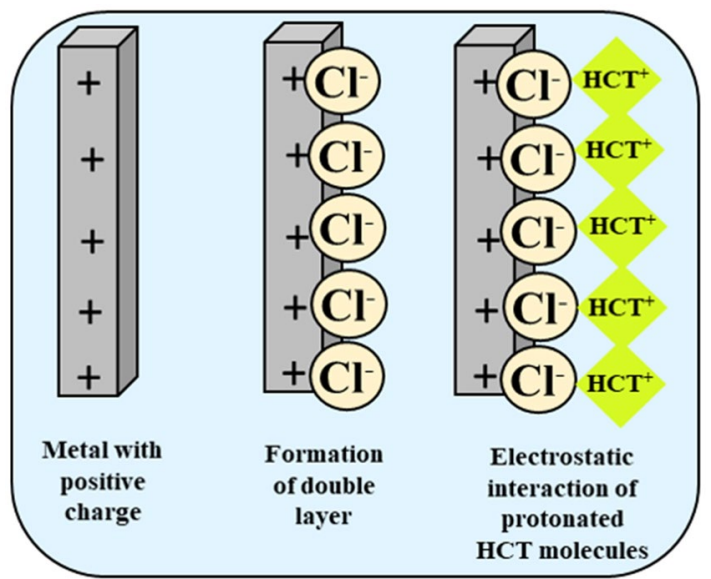

Fig. 8 Schematic representation of mechanism of corrosion inhibition by HCT

Optimized structure of inhibitor molecule and its frontier molecular orbitals are shown in Fig. 9.

As discussed earlier, the inhibitor molecule probably gets protonated in an aqueous acidic medium, taking part in the physical adsorption process. Therefore, it becomes essential to understand the electron population or electron density distribution in the inhibitor molecule. Mostly, the most preferred site of protonation is the heteroatoms of an inhibitor molecule having the most negative Mulliken charges [44, 45]. Mulliken charge distribution in various heteroatoms present in HCT is given schematically in Fig. 10 and recorded in Table 6.

Optimized structure of protonated inhibitor molecule and its frontier electron density distribution is shown in the following Fig. 11.

Various parameters of quantum chemical study for neutral and protonated molecules are calculated and tabulated in Table 7.

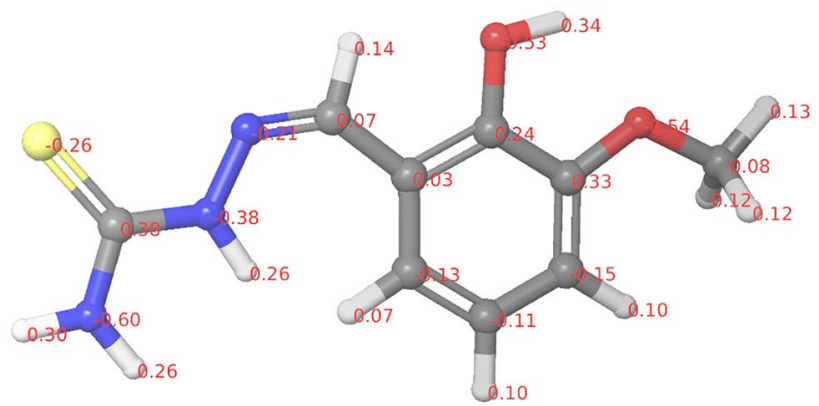

Fig. 10 Schematic representation of Mulliken charge distribution

The molecular orbital energies of the FMO can be related to the ionization potential and electron affinity as per Koopman's theorem, given in the Eqs. (12) and (13) [46-48]

$-\mathrm{E}_{\mathrm{HOMO}}=\mathrm{I}$

$-\mathrm{E}_{\mathrm{LUMO}}=\mathrm{A}$

where I is the ionization potential and A denotes the electron affinity. The electronegativity and hardness can be obtained using above parameters as per the Eqs. (14) and (15)

$\chi=\frac{1}{2}(I+A)$

$\eta=\frac{1}{2}(I-A)=\frac{1}{\sigma}$

where $\chi$ symbolizes the absolute electronegativity, $\eta$ indicates the chemical hardness, and $\sigma$ is the reciprocal of hardness(global softness). The electrophilicity index $(\omega)$ and its inverse, the nucleophilicity $(\varepsilon)$, can be calculated using Eq. (16)

Fig. 9 Optimised structure and frontier orbital electron density distribution for neutral HCT

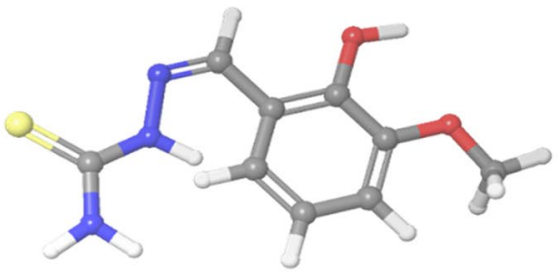

Neutral
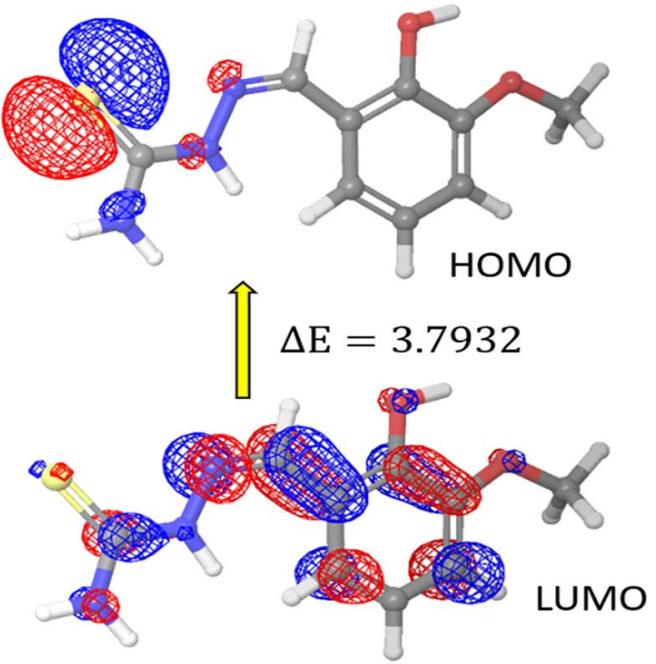
Table 6 Mulliken charges on heteroatoms of HCT

\begin{tabular}{lllllll}
\hline Heteroatom & $\mathrm{O}(7)$ & $\mathrm{O}(8)$ & $\mathrm{N}(14)$ & $\mathrm{N}(15)$ & $\mathrm{N}(17)$ & $\mathrm{S}(18)$ \\
\hline Mullikan charge & -0.5428 & -0.5267 & -0.2123 & -0.3848 & -0.5970 & -0.2620 \\
\hline
\end{tabular}

Table 7 Quantum chemical parameters of the neutral and protonated HCT
Fig. 11 Optimised structure and frontier orbital electron density distribution for protonated HCT
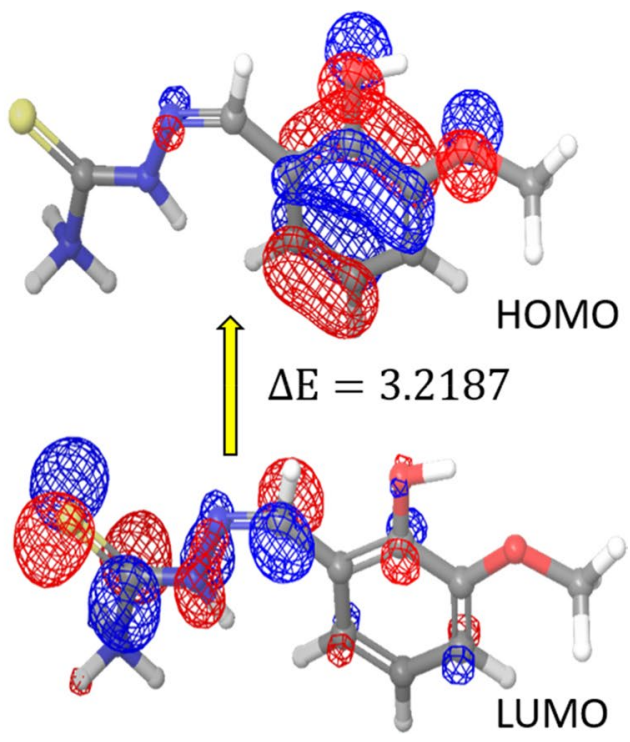

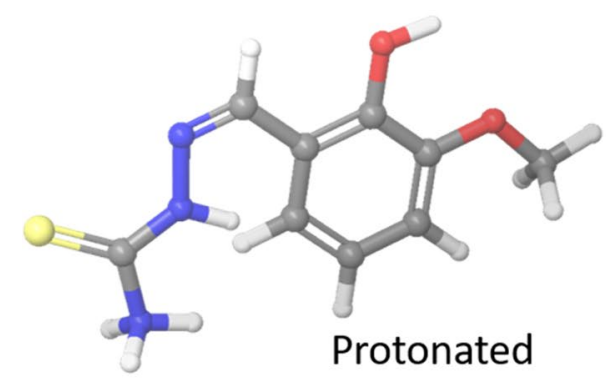

All energy values are in $\mathrm{eV}, \mu$ in Debye, $\sigma$ is in $\mathrm{eV}^{-1}$

$\omega=\frac{\chi^{2}}{4 \eta}=\frac{1}{\varepsilon}$

Fraction of electron transferred $(\Delta N)$ was computed using the values of electronegativity $(\chi)$ and chemical hardness $(\eta)$ [47-49] using the relation (17)

$\Delta N=\frac{\phi_{\mathrm{Al}}-\chi_{\mathrm{inh}}}{2 \eta_{\mathrm{inh}}}$

where $\phi \mathrm{Al}$ is the work function of the Aluminium $(4.08 \mathrm{eV})$.

It is evident from the above Table 7 that, after protonation, the inhibitor molecule showed a remarkable decrease in the $\mathrm{E}_{\text {Hомо }}$ value compared to that of the unprotonated molecule. That means electron donating ability decreased significantly. At the same time, $E_{\mathrm{LUMO}}$ value also reduced to a considerable extent. This clearly suggested that after protonation electronaccepting capacity of the inhibitor increased. After protonation, the global electronegativity $(\chi)$ became almost double. In the case of protonated inhibitor molecule, electrophilicity index $(\omega)$ increased, and nucleophilicity $(\in)$ decreased to a large extent. All these resulted in the decrease in the energy gap $(\Delta E)$ between $E_{\mathrm{HOMO}}$ and $E_{\mathrm{LUMO}}$ leading to the stable layer formation on the surface of composite material.

For a neutral HCT, the fraction of electron transferred $(\Delta N)$ is 0.20 , whereas, for protonated HCT molecule, it is -1.00 . This suggested that a neutral molecule can donate electrons, whereas, after protonation, its electron donating capacity is decreased and its tendency to accept electrons increased many folds [46]. This again supported and supplemented the physical adsorption of protonated HCT molecules onto the surface of composite material.

Dipole moment $(\mu)$ of the neutral HCT is 8.70 Debye. This is higher than the dipole moment of water (1.88 Debye). After protonation, dipole moment is 11.67 Debye. The large increase in the value of dipole moment for protonated molecule confirmed its adsorption on metallic surface replacing water molecule [50]. 


\subsection{Surface Morphological Studies}

\subsubsection{Scanning Electron Microscopy (SEM)}

The surface morphology, as observed under SEM, under varying experimental condition are shown in Fig. 12. The SEM image Fig. 12a is for un-corroded composite material. The surface is inhomogeneous and rough because of reinforced particles. The SEM image Fig. $12 b$ shows the specimen dipped in a $0.5 \mathrm{M} \mathrm{HCl}$ solution. The surface is uneven and a large number of cavities can be found. These cavities are due to the removal of $\mathrm{SiC}$ particulates from the matrix when the specimen was in contact with the acid because of corrosion. The presence of chloride ions further accelerates the pit formation, and hence corrosion will be more. The SEM image Fig. 12c shows the surface of the specimen dipped in $0.5 \mathrm{M} \mathrm{HCl}$, which had a $10 \times 10^{-5} \mathrm{M}$ concentration of HCT. The addition of HCT makes the surface relatively smoother. This may be due to the adsorption of HCT molecules in the cavities which were formed due to corrosion and on the surface as well.

\subsubsection{Atomic Force Microscopy (AFM)}

The 3D AFM images of composite material under different experimental conditions are presented in Fig. 13. Figure 13a is image of the freshly polished metal surface, Fig. 13b represents the surface of the specimen dipped in $0.5 \mathrm{M} \mathrm{HCl}$, and image Fig. $13 \mathrm{c}$ represents the surface of the specimen dipped in $0.5 \mathrm{M} \mathrm{HCl}$ containing $10 \times 10^{-5} \mathrm{M}$ concentration of HCT. Average roughness $\left(R_{\mathrm{a}}\right)$, root mean square roughness $\left(R_{\mathrm{q}}\right)$, and the maximum roughness $\left(R_{\max }\right)$ were estimated. From Table 8 , it can be observed that all the three roughness values for the freshly polished metal are lesser when compared with the other two. The roughness values for the specimen dipped only in $\mathrm{HCl}$ solution is large when compared with that of the specimen dipped in $\mathrm{HCl}$ containing HCT. This
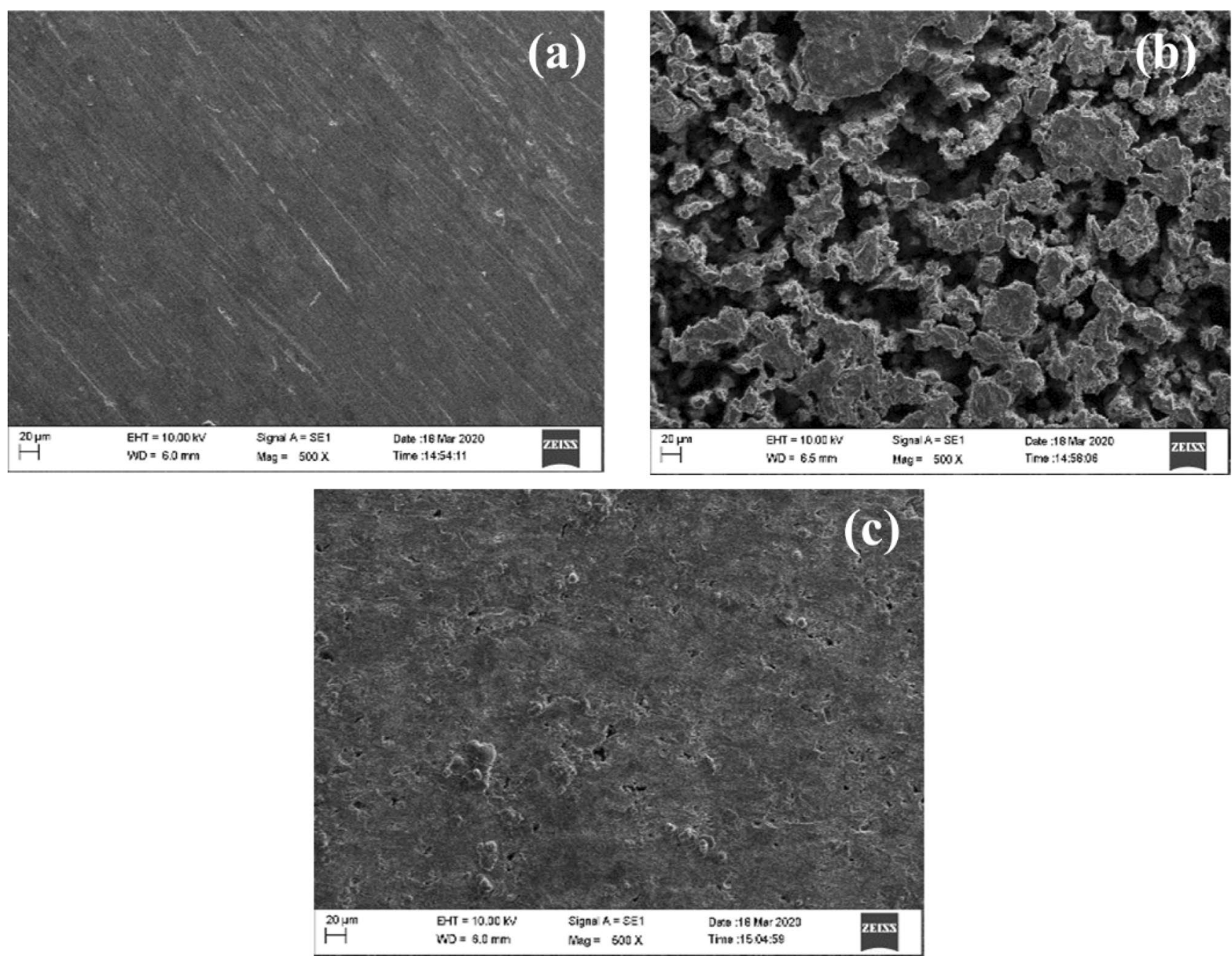

Fig. 12 SEM images a freshly polished Al-composite, b Al-composite $+0.5 \mathrm{M} \mathrm{HCl}$, c Al-composite $+0.5 \mathrm{M} \mathrm{HCl}+10 \times 10^{-5} \mathrm{M} \mathrm{HCT}$ 


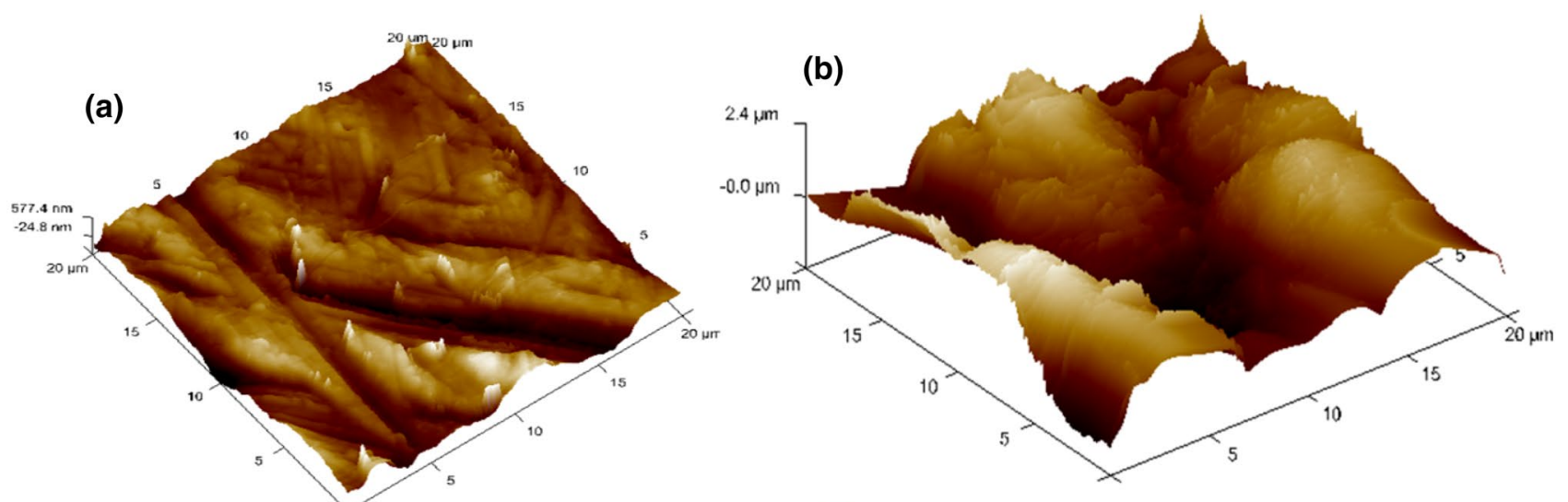

(c)

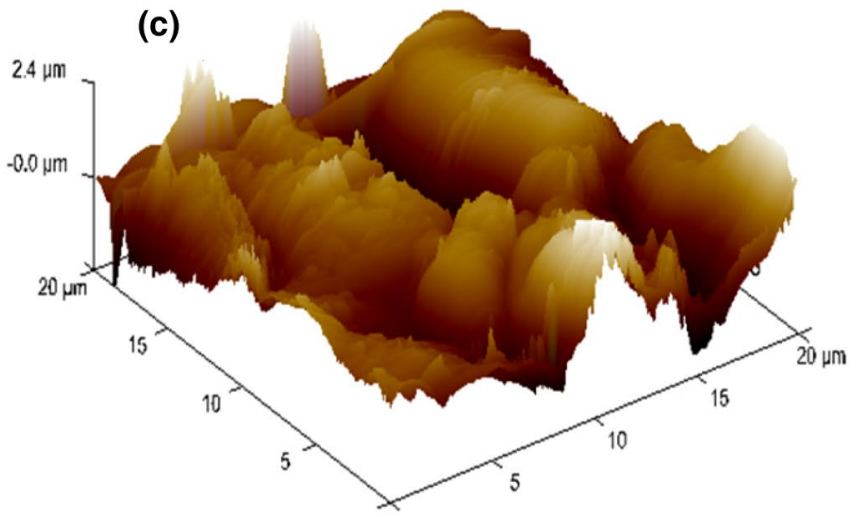

Fig. 13 AFM images of a freshly polished Al-composite material, b Al-composite material $+0.5 \mathrm{M} \mathrm{HCl}$, c Al-composite material $+0.5 \mathrm{M}$ $\mathrm{HCl}+10 \times 10^{-5} \mathrm{M} \mathrm{HCT}$

Table 8 Surface Roughness data obtained for different specimen of Al-composite

\begin{tabular}{llll}
\hline Sample & $R_{\mathrm{a}}(\mathrm{nm})$ & $R_{\mathrm{q}}(\mathrm{nm})$ & $R_{\max }(\mathrm{nm})$ \\
\hline Freshly polished Al-composite & 80.5 & 105 & 1425 \\
Al-composite $+0.5 \mathrm{M} \mathrm{HCl}$ & 709 & 855 & 4657 \\
Al-composite $+0.5 \mathrm{M}$ & 328 & 421 & 3828 \\
$\mathrm{HCl}+10 \times 10^{-5}$ M HCT & & & \\
\hline
\end{tabular}

indicated that HCT molecules are binding the surface and making it less rough.

\subsection{Limitation and Future Direction}

Though inhibition efficiency for this system is not very high, this study helps to try for other large molecules of hetero atom organic compounds to function as inhibitor, its moiety part effectively blocking large surface area of the metal hindering anodic reaction when adsorbed and by forming a stable film, and/or increasing overvoltage for Cathodic reaction.

Corrosion control studies using chemical inhibitor is time tested, well accepted method for material conservation in Industries. Every year lots of compounds are being synthesized and screened for their anticorrosive properties. The compound we tried emerged as a good inhibitor for corrosion control of aluminum composite material. However, there is scope to improve upon the efficacy of inhibitor by varying experimental conditions such as temperature and acid concentration. Further, efficiency of inhibitor can also be improved by synthesizing analogous series of compounds with different substitution groups. In our present work we have done a detailed quantum chemical calculation to substantiate the mechanism of corrosion. Further studies can be done by applying simulation condition as well. The inhibitor and its homologous series can be tried to prevent corrosion of other engineering materials such as steel, copper and zinc under varying experimental conditions.

\section{Conclusions}

The synthesized inhibitor HCT was found to effectively inhibit the corrosion of $\mathrm{Al}$-composite in $0.5 \mathrm{M}$ hydrochloric acid medium.

- Upon increase in the HCT concentration, I.E\%. increased

- I.E.\% decreased with an increase in the temperature. 
- The maximum efficiency was found to be $56.8 \%$ at $303 \mathrm{~K}$, for $10 \times 10^{-5} \mathrm{M}$ HCT.

- HCT functioned as a mixed inhibitor, showed physical adsorption, and followed Langmuir adsorption isotherm when adsorption of it took place on the surface of Alcomposite corroding in $0.5 \mathrm{M} \mathrm{HCl}$.

- Surface morphology studies confirmed the adsorption of HCT on the composite surface.

- Quantum chemical calculations reaffirmed the physical adsorption of inhibitor.

Acknowledgements Authors acknowledge the laboratory facility extended by Department of Chemistry, MIT, MAHE.

Funding Open access funding provided by Manipal Academy of Higher Education, Manipal.

\section{Declarations}

Conflict of interest On behalf of all authors, corresponding author claims no conflict of interest.

Open Access This article is licensed under a Creative Commons Attribution 4.0 International License, which permits use, sharing, adaptation, distribution and reproduction in any medium or format, as long as you give appropriate credit to the original author(s) and the source, provide a link to the Creative Commons licence, and indicate if changes were made. The images or other third party material in this article are included in the article's Creative Commons licence, unless indicated otherwise in a credit line to the material. If material is not included in the article's Creative Commons licence and your intended use is not permitted by statutory regulation or exceeds the permitted use, you will need to obtain permission directly from the copyright holder. To view a copy of this licence, visit http://creativecommons.org/licenses/by/4.0/.

\section{References}

1. Monticelli C, Zucchi F, Brunoro G, Trabanelli G (1997) Corrosion and corrosion inhibition of alumina particulate/aluminium alloys metal matrix composites in neutral chloride solutions. J Appl Electrochem 27:325-334

2. Reena Kumari PD, Nayak J, Nityananda Shetty A (2016) Corrosion behavior of 6061/Al-15 vol. pct. $\mathrm{SiC}(\mathrm{p})$ composite and the base alloy in sodium hydroxide solution. Arab J Chem 9:S1144 S1154. https://doi.org/10.1016/j.arabjc.2011.12.003

3. Charitha BP, Rao P (2017) An ecofriendly approach for corrosion control of $6061 \mathrm{Al}-15 \%$ (v) $\mathrm{SiC}(\mathrm{P})$ composite and its base alloy. Chinese J Chem Eng 25:363-372. https://doi.org/10.1016/j.cjche.2016.08.007

4. Charitha BP, Rao P (2018) Environmentally benign green inhibitor to attenuate acid corrosion of 6061Aluminum-15\%(v) $\operatorname{SiC}(\mathrm{P})$ composite. J Ind Eng Chem 58:357-368. https://doi.org/10.1016/j. jiec.2017.09.049

5. Pinto GM, Nayak J, Shetty AN (2009) Corrosion behaviour of $6061 \mathrm{Al}-15$ vol. Pct. SiC composite and its base alloy in a mixture of 1:1 hydrochloric and sulphuric acid medium. Int J Electrochem Sci 4:1452-1468

6. Abbass MK, Hassan KS, Alwan AS (2015) Study of corrosion resistance of aluminum alloy $6061 / \mathrm{SiC}$ composites in $3.5 \% \mathrm{NaCl}$ solution. Int J Mater Mech Manuf 3:31-35. https://doi.org/10. 7763/ijmmm.2015.v3.161

7. Shetty SK, Shetty AN (2015) Ionic Liquid as an effective corrosion inhibitor on $6061 \mathrm{Al}-15$ Vol. Pct. $\mathrm{SiC}(\mathrm{p})$ composite in 0.1 $\mathrm{M} \mathrm{H}_{2} \mathrm{SO}_{4}$ medium - an ecofriendly approach. Can Chem Trans 3:42-64. https://doi.org/10.13179/canchemtrans.2015.03.01.0160

8. Xhanari K, Finšgar M (2019) Organic corrosion inhibitors for aluminum and its alloys in chloride and alkaline solutions: a review. Arab J Chem 12:4646-4663. https://doi.org/10.1016/j.arabjc. 2016.08.009

9. Xhanari K, Finšgar M (2016) Organic corrosion inhibitors for aluminium and its alloys in acid solutions: a review. RSC Adv 6:62833-62857. https://doi.org/10.1039/c6ra11818f

10. Xu B, Yang W, Liu Y, Yin X, Gong W, Chen Y (2014) Experimental and theoretical evaluation of two pyridinecarboxaldehyde thiosemicarbazone compounds as corrosion inhibitors for mild steel in hydrochloric acid solution. Corros Sci 78:260-268. https://doi.org/10.1016/j.corsci.2013.10.007

11. Goulart CM, Esteves-Souza A, Martinez-Huitle CA, Rodrigues CJF, Maciel MAM, Echevarria A (2013) Experimental and theoretical evaluation of semicarbazones and thiosemicarbazones as organic corrosion inhibitors. Corros Sci 67:281-291. https:// doi.org/10.1016/j.corsci.2012.10.029

12. Zhang HH, Chen Y (2019) Experimental and theoretical studies of benzaldehyde thiosemicarbazone derivatives as corrosion inhibitors for mild steel in acid media. J Mol Struct 1177:90100. https://doi.org/10.1016/j.molstruc.2018.09.048

13. Zhang HH, Chen Y, Zhang Z (2018) Comparative studies of two benzaldehyde thiosemicarbazone derivatives as corrosion inhibitors for mild steel in 1.0 M HCl. Results Phys 11:554-563. https://doi.org/10.1016/j.rinp.2018.09.038

14. El Azzouzi M, Aouniti A, Tighadouin S, Elmsellem H, Radi S, Hammouti B, El Assyry A, Bentiss F, Zarrouk A (2016) Some hydrazine derivatives as corrosion inhibitors for mild steel in 1.0 M HCl: weight loss, electrochemichal, SEM and theoretical studies. J Mol Liq 221:633-641. https://doi.org/10.1016/j. molliq.2016.06.007

15. Khaled KF (2006) Experimental and theoretical study for corrosion inhibition of mild steel in hydrochloric acid solution by some new hydrazine carbodithioic acid derivatives. Appl Surf Sci 252:4120-4128. https://doi.org/10.1016/j.apsusc.2005.06. 016

16. Abd El-Lateef HM (2020) Corrosion inhibition characteristics of a novel salycilidene isatin hydrazine sodium sulfonate on carbon steel in $\mathrm{HCl}$ and a synergistic nickel ions additive: a combined experimental and theoretical perspective. Appl Surf Sci 501:144237. https://doi.org/10.1016/j.apsusc.2019.144237

17. Fouda AS, El-Maksoud SAA, El-Hossiany A, Ibrahim A (2019) Evolution of the corrosion-inhibiting efficiency of novel hydrazine derivatives against corrosion of stainless steel 201 in acidic medium. Int J Electrochem Sci 14:6045-6064. https://doi.org/10. 20964/2019.07.65

18. Kumari PDR, Nayak J, Shetty AN (2014) Corrosion inhibition of 6061 Al-15 vol. pct. SiC(p) composite in sodium hydroxide solution by 4-amino-5-(4-nitrophenyl)-4H-1,2,4-triazole-3-thiol. Procedia Mater Sci 5:181-187. https://doi.org/10.1016/j.mspro. 2014.07.256

19. Kini UA, Shetty P, Shetty SD, Isloor MA (2011) Corrosion inhibition of Al6061- SiCp composite in $0.5 \mathrm{M}$ hydrochloric acid. In: International conference on chemistry and chemical process. pp 127-132

20. Pinto GM, Nayak J, Shetty AN (2011) Corrosion inhibition of 6061 Al-15 vol. pct. $\mathrm{SiC}(\mathrm{p})$ composite and its base alloy in a mixture of sulphuric acid and hydrochloric acid by $4-(N, N$-dimethyl amino) benzaldehyde thiosemicarbazone. Mater Chem Phys 125:628-640. https://doi.org/10.1016/j.matchemphys.2010.10.006 
21. Khandani M, Sedaghat T, Erfani N, Haghshenas MR, Khavasi HR (2013) Synthesis, spectroscopic characterization, structural studies and antibacterial and antitumor activities of diorganotin complexes with 3-methoxysalicylaldehyde thiosemicarbazone. J Mol Struct 1037:136-143. https://doi.org/10.1016/j.molstruc. 2012.12.061

22. Prakashaiah BG, Vinaya Kumara D, Anup Pandith A, Nityananda Shetty A, Amitha Rani BE (2018) Corrosion inhibition of 2024-T3 aluminum alloy in $3.5 \% \mathrm{NaCl}$ by thiosemicarbazone derivatives. Corros Sci 136:326-338. https://doi.org/10.1016/j.corsci.2018.03.021

23. Singh P, Ebenso EE, Olasunkanmi LO, Obot IB, Quraishi MA (2016) Electrochemical, theoretical, and surface morphological studies of corrosion inhibition effect of green naphthyridine derivatives on mild steel in hydrochloric acid. J Phys Chem C 120:3408-3419. https://doi.org/10.1021/acs.jpcc.5b11901

24. Verma C, Olasunkanmi LO, Ebenso EE, Quraishi MA, Obot IB (2016) Adsorption behavior of glucosamine-based, pyrimidinefused heterocycles as green corrosion inhibitors for mild steel: experimental and theoretical studies. J Phys Chem C 120:1159811611. https://doi.org/10.1021/acs.jpcc.6b04429

25. Ansari KR, Quraishi MA, Singh A, Ramkumar S, Obote IB (2016) Corrosion inhibition of $\mathrm{N} 80$ steel in $15 \% \mathrm{HCl}$ by pyrazolone derivatives: electrochemical, surface and quantum chemical studies. RSC Adv 6:24130-24141. https://doi.org/10.1039/c5ra25441h

26. Rao CNR, Venkataraghavan $\mathrm{R}$ (1962) The $\mathrm{C}=\mathrm{S}$ stretching irequency and the "-N-C=S bands" in the infrared. Spectrochim Acta 18:541-547

27. Khadiri A, Saddik R, Bekkouche K, Aouniti A, Hammouti B, Benchat N, Bouachrine M, Solmaz R (2016) Gravimetric, electrochemical and quantum chemical studies of some pyridazine derivatives as corrosion inhibitors for mild steel in $1 \mathrm{M} \mathrm{HCl}$ solution. J Taiwan Inst Chem Eng 58:552-564. https://doi.org/10. 1016/j.jtice.2015.06.031

28. Abd El-Maksoud SA, Fouda AS (2005) Some pyridine derivatives as corrosion inhibitors for carbon steel in acidic medium. Mater Chem Phys 93:84-90. https://doi.org/10.1016/j.matchemphys. 2005.02.020

29. Li WH, He Q, Zhang ST, Pei CL, Hou BR (2008) Some new triazole derivatives as inhibitors for mild steel corrosion in acidic medium. J Appl Electrochem 38:289-295. https://doi.org/10. 1007/s10800-007-9437-7

30. Charitha BP, Rao P (2017) Carbohydrate biopolymer for corrosion control of 6061 Al-alloy and 6061Aluminum-15\%(v) SiC(P) composite-green approach. Carbohydr Polym 168:337-345. https:// doi.org/10.1016/j.carbpol.2017.03.098

31. Charitha BP, Rao P (2018) Pullulan as a potent green inhibitor for corrosion mitigation of aluminum composite: electrochemical and surface studies. Int J Biol Macromol 112:461-472. https://doi.org/ 10.1016/j.ijbiomac.2018.01.218

32. Shetty D, Kumari PP, Rao SA, Shetty P (2020) Anticorrosion behaviour of a hydrazide derivative on $6061 \mathrm{Al}-15 \%$ (v) $\mathrm{SiC}(\mathrm{P})$ composite in acid medium: experimental and theoretical calculations. J Bio- Tribo-Corrosion 6:1-15. https://doi.org/10.1007/ s40735-020-00356-9

33. Charitha BP, Rao P (2017) Electrochemical and adsorption studies for the corrosion control of $6061 \mathrm{Al}$ alloy using eco-friendly inhibitor. Surf Eng Appl Electrochem 53:551-559. https://doi.org/ 10.3103/S1068375517060035

34. Khaled KF (2008) Guanidine derivative as a new corrosion inhibitor for copper in 3\% NaCl solution. Mater Chem Phys 112:104111. https://doi.org/10.1016/j.matchemphys.2008.05.052

35. Larouj M, Ourrak K, El M'Rabet M, Zarrok H, Serrar H, Boudalia M, Boukhriss S, Warad I, Oudda H, Touir R (2017) Thermodynamic study of corrosion inhibition of carbon steel in acidic solution by new pyrimidothiazine derivative. J Mater Environ Sci 8:3921-3931
36. Ikeuba AI, Ita BI, Etiuma RA, Bassey VM, Ugi BU, Kporokpo EB, Chemistry A (2015) Green corrosion inhibitors for mild steel in $\mathrm{H}_{2} \mathrm{SO}_{4}$ solution: flavonoids of gongronema latifolium. Chem Process Eng Res 34:1-10

37. Ashassi-Sorkhabi H, Shaabani B, Seifzadeh D (2005) Corrosion inhibition of mild steel by some schiff base compounds in hydrochloric acid. Appl Surf Sci 239:154-164. https://doi.org/10. 1016/j.apsusc.2004.05.143

38. Şahin M, Bilgiç S, Yilmaz H (2002) The inhibition effects of some cyclic nitrogen compounds on the corrosion of the steel in $\mathrm{NaCl}$ mediums. Appl Surf Sci 195:1-7. https://doi.org/10.1016/ S0169-4332(01)00783-8

39. Kshama Shetty S, Nityananda Shetty A (2017) Eco-friendly benzimidazolium based ionic liquid as a corrosion inhibitor for aluminum alloy composite in acidic media. J Mol Liq 225:426-438. https://doi.org/10.1016/j.molliq.2016.11.037

40. Xhanari K, Finsgar M (2019) Organic corrosion inhibitors for aluminum and its alloys in chloride and alkaline solutions: a review. Arab J Chem 12:4646-4663. https://doi.org/10.1016/j.arabjc. 2016.08.009

41. Belkhaouda M, Bammou L, Zarrouk A, Salghi R, Ebenso EE, Zarrok H, Hammouti B, Bazzi L, Warad I (2013) Inhibition of c-steel corrosion in hydrochloric solution with chenopodium ambrorsioides extract. Int J Electrochem Sci 8:7425-7436

42. Gupta NK, Verma C, Salghi R, Lgaz H, Mukherjee AK, Quraishi MA (2017) New phosphonate based corrosion inhibitors for mild steel in hydrochloric acid useful for industrial pickling processes: experimental and theoretical approach. New J Chem 41:13114 13129. https://doi.org/10.1039/c7nj01431g

43. Arukalam IO (2014) Durability and synergistic effects of KI on the acid corrosion inhibition of mild steel by hydroxypropyl methylcellulose. Carbohydr Polym 112:291-299. https://doi.org/ 10.1016/j.carbpol.2014.05.071

44. Gao G, Liang C (2007) Electrochemical and DFT studies of $\beta$-amino-alcohols as corrosion inhibitors for brass. Electrochim Acta 52:4554-4559. https://doi.org/10.1016/j.electacta.2006.12.058

45. Hasanov R, Sadikoğlu M, Bilgiç S (2007) Electrochemical and quantum chemical studies of some Schiff bases on the corrosion of steel in $\mathrm{H}_{2} \mathrm{SO}_{4}$ solution. Appl Surf Sci 253:3913-3921. https:// doi.org/10.1016/j.apsusc.2006.08.025

46. Obot IB, Macdonald DD, Gasem ZM (2015) Density functional theory (DFT) as a powerful tool for designing new organic corrosion inhibitors: part 1: an overview. Corros Sci 99:1-30. https:// doi.org/10.1016/j.corsci.2015.01.037

47. Geerlings P, De Proft F, Langenaeker W (2003) Conceptual density functional theory. Chem Rev 103:1793-1873. https://doi.org/ $10.1021 / \mathrm{cr} 990029 \mathrm{p}$

48. Chauhan DS, Ansari KR, Sorour AA, Quraishi MA, Lgaz H, Salghi R (2018) Thiosemicarbazide and thiocarbohydrazide functionalized chitosan as ecofriendly corrosion inhibitors for carbon steel in hydrochloric acid solution. Int J Biol Macromol 107:1747-1757. https://doi.org/10.1016/j.ijbiomac.2017.10.050

49. Obot IB, Ebenso EE, Kabanda MM (2013) Metronidazole as environmentally safe corrosion inhibitor for mild steel in $0.5 \mathrm{M} \mathrm{HCl}$ : experimental and theoretical investigation. J Environ Chem Eng 1:431-439. https://doi.org/10.1016/j.jece.2013.06.007

50. Idir B, Kellou-Kerkouche F (2018) Experimental and theoretical studies on corrosion inhibition performance of phenanthroline for cast iron in acid solution. J Electrochem Sci Technol 9:260-275. https://doi.org/10.33961/jecst.2018.9.4.260

Publisher's Note Springer Nature remains neutral with regard to jurisdictional claims in published maps and institutional affiliations. 